\title{
A organização do trabalho prisional e as vivências de prazer e sofrimento
}

Jaqueline Oliveira Bagalho. Associação Vitoriana de Ensino Superior Thiago Drumond Moraes. Universidade Federal do Espírito Santo

\section{Resumo}

O trabalho do inspetor penitenciário é marcado por meios de trabalho precarizados, sobrecarga física e mental, convívio com situações de violência e estigmatização social, produzindo efeitos nos processos saúde-doença mental. Visando compreender esses processos, objetivou-se identificar relações entre vivência de sofrimento-prazer dos trabalhadores e organização do trabalho. Baseado na Psicodinâmica do Trabalho realizou-se 19 entrevistas semiestruturadas com inspetores penitenciários do Espírito Santo. Verificou-se que a gestão, baseada em duas formas de contrato e promoção mediante apadrinhamento, fragiliza o coletivo de trabalho e ativa a dessubjetivação, bloqueando a cooperação e o reconhecimento. Defesas como a ideologia defensiva contra o medo são partilhadas, contudo dificultam a atribuição de sentido consensual ao trabalho. Há indícios de que a vivência de prazer é possibilitada pela reapropriação do trabalho e mobilização de estratégias defensivas individuais. Melhorar esse quadro requer legitimar o saber-fazer do trabalhador, garantindo condições idênticas de trabalho a ambos os tipos de contrato. Palavras-chave: saúde ocupacional; prisões; saúde mental; psicodinâmica.

\begin{abstract}
The organization of the prison work and experiences of pleasure and suffering. The work of prison inspector is marked by precarious work conditions, physical and mental overload, contact with violence and social stigmatization situations, producing effects on mental health-illness processes. Seeking to understand these processes, this study aimed to identify relationships between experience of pleasure-suffering of employees and work organization. Based on the psychodynamics of work, were conducted 19 semi-structured interviews with Espírito Santo's prison inspectors. It was found that the management, based on two forms of contract and promotion through cronyism, weakens the collective work and activates the desubjectivation, blocking cooperation and recognition. Defenses as defensive ideology against fear are shared, but they hinder the attribution of consensual meaning to work. There are indication that the experience of pleasure is made possible by re-appropriation of work and mobilization of individual defensive strategies. Improving this situation requires legitimize the know-how of the employee, ensuring identical working conditions for both types of contracts.
\end{abstract}

Keywords: occupational health; prisons; mental health; psychodynamics.

\section{Resumen}

La organización del trabajo de las prisiones y las experiencias de placer y sufrimiento. El trabajo del inspector de la cárcel se caracteriza por ambientes precarios, sobrecarga física y mental, contacto con situaciones de violencia y estigmatización social, produciendo efectos sobre procesos de salud y enfermedad mentales. Tratando de entender estos procesos dirigidos a identificar las relaciones entre la experiencia de placer-sufrimiento y la organización del trabajo. Sobre la base de la psicodinámica del trabajo se llevaron a cabo 19 entrevistas semiestructuradas con el personal penitenciario del departamento de Espírito Santo. Se observó que la gestión, basada en dos formas de contrato y la promoción a través de patrocinio, debilita la negociación colectiva y activa la desubjetivación, el bloqueo de la cooperación y el reconocimiento. La ideología defensiva contra el miedo se comparten e no hay consenso sobre el sentido del trabajo. La mejora de esta situación requiere legitimar el saber-hacer de los inspectores, asegurando condiciones de trabajo idénticas para ambos tipos de contratos.

Palabras clave: salud ocupacional; prisiones; salud mental; psicodinámica. 
A concepção acerca do trabalho se apresenta intimamente ligada ao momento histórico-social. No que tange a esse aspecto, pode-se observar uma mudança radical do status social do trabalho, especialmente, dos períodos históricos da Idade Antiga para a Moderna. A utilidade econômica atribuída ao trabalho, já na Idade Moderna, modificou seu status, o inscrevendo entre as atividades mais valorosas da sociedade, atrelando ao homem trabalhador as honras mais estimadas (Arendt, 2016; Dejours, Barros, \& Lancman, 2016, Schwartz, 2000).

O trabalho na prisão, em contrapartida, testemunhou muito sutilmente essas transformações, no que concerne aos inspetores penitenciários, esse ofício, ainda carrega o estigma de carcereiro (Varella, 2012). Historicamente, essa profissão tem sido confrontada com a vivência de estereótipos e baixo status social, ao mesmo tempo em que estão inseridos em um contexto, ambiente de trabalho, tensionado por relações conflituosas e situações de risco (Finney, 2013; Goffman, 2013). Segundo dados do sistema Infopen, sobre informações penitenciárias (Ministério da Justiça, 2014), o Brasil conta com mais de 45 mil inspetores penitenciários em exercício profissional, os quais convivem cotidianamente com a violência (Lopes, 2002).

\section{O Trabalho Prisional}

São frequentes os estudos que referem o sistema prisional brasileiro aos temas da tortura ou desrespeito às condutas éticas no que se refere às diretrizes dos Direitos Humanos (Zackseski, Machado, \& Azevedo, 2016). Teóricos vêm destacando as peculiaridades desse ambiente que conta com características insalubres e perniciosas à saúde dos seus ocupantes sejam apenados ou trabalhadores (Goffman, 2013; Thompson, 2002).

Os inspetores de segurança penitenciária representam a categoria responsável pela manutenção e custódia dos apenados, sendo a descrição básica da atribuição do Inspetor Penitenciário: "efetuar a segurança da Unidade Penal em que atua, mantendo a disciplina. Vigiar, fiscalizar, inspecionar, revistar e acompanhar os presos ou internados, zelando pela ordem e segurança deles, bem como da Unidade Penal" (Perfil Profissiográfico, 2004). Além de custodiar, existe uma expectativa para que participem como atores no processo de reintegração social dos apenados, estando instituída em sua missão: "participar ativamente do processo de reintegração social da pessoa privada de liberdade sendo co-responsável pela manutenção da segurança no ambiente prisional" (Secretaria de Estado da Justiça/ES, s.d). Existem duas formas de ingresso na profissão: concurso público para enquadramento em regime efetivo e processo seletivo simplificado para contratação em designação temporária (DT) por dois anos (prorrogáveis por até mais dois anos).

Segundo último Relatório Anual do Sistema Penitenciário Capixaba publicado em fevereiro de 2013 (Secretaria de Estado da Justiça/ES, 2013), houve um aumento de $78 \%$ da população carcerária estadual entre os períodos de março 2003 a junho de 2012. De acordo com relatório de quantitativo da população carcerária (Secretaria de Estado da Justiça/ES, 2015), atualmente o Estado conta com uma população encarcerada que ultrapassa 18 mil pessoas, entre homens e mulheres, ocupando a oitava posição no ranking brasileiro quanto ao número de pessoas presas.

Segundo Lopes (2002) o trabalho de custodiar a vida dos apenados e a preocupação em evitar as fugas, a superpopulação prisional e a carência de funcionários no setor de segurança das prisões gera uma sobrecarga de trabalho que intensifica o desgaste físico e mental desses profissionais. Além da sobrecarga, verificou-se em diferentes estados brasileiros que as condições de trabalho expõem os trabalhadores a constantes riscos de violência e de exposição a cargas biológicas, criando uma atmosfera de insatisfação e tensão, aumentando a exposição a situações ansiogênicas, o que repercute de maneira negativa na saúde física e mental, e que produz um nível de satisfação profissional baixíssimo (França, 2011; Garcia, 2008; Rumin, Barros, Cardozo, Cavalhero, \& Atelli, 2011; Vasconcelos, 2000).

Diante do contexto e das condições de trabalho apresentadas, propusemos a presente pesquisa com o objetivo de identificar e analisar as relações entre a vivência de sofrimento e prazer dos trabalhadores penitenciários e a Organização do Trabalho. Para trilhar esse caminho a perspectiva teórico-metodológica utilizada foi a Psicodinâmica do Trabalho (PdT).

\section{Trabalho - A Psicodinâmica do Sofrimento e Prazer}

O trabalho é definido por Dejours (2011, p. 78) como a "atividade manifestada por homens e mulheres para realizar o que ainda não está prescrito pela organização do trabalho". Nesta lacuna entre o prescrito e o real está a ação humana que se denomina trabalho. Dejours, (2003) define o real como a dimensão não-prescrita e, por isso, inusitada do trabalho, trata-se, pois, da dimensão que engaja subjetivamente o trabaIhador no trabalho. 
O sofrimento acaba por se configurar como pano de fundo do universo do trabalho, já que "é proveniente e consubstanciado em toda situação laboral, pois representa, antes de tudo, encontrar-se diante do conjunto de constrangimentos sistêmicos e técnicos" Dejours (2011, p. 88). Assim, Dejours, Abdouchelli e Jayet (1994), identificam dois tipos específicos de sofrimento: o patogênico e o criativo. O patogênico se traduz como o fracasso após a exploração de todos os recursos defensivos do indivíduo, como espécie de resíduo não compensado, que leva a uma destruição do equilíbrio psíquico do sujeito, empurrando-o para uma lenta e brutal destruição orgânica. Em relação ao sofrimento criativo, Dejours et al. (1994) o define como capacidade do indivíduo elaborar soluções originais que favorecem ou restituem sua saúde. O sofrimento criativo chega a adquirir um sentido, pois favorece ao indivíduo um reconhecimento de uma identidade.

O sofrimento só pode ser acessado por meio das defesas e "a vocação primeira dessas defesas é a de resistir psiquicamente à agressão que constitui determinadas formas de organizações de trabalho" (Dejours, 2011, p. 171). Em outras palavras, se eficazes, as defesas podem mascarar ou esconder o sofrimento, a ponto de ignorá-lo completamente. As defesas, nessa perspectiva, de acordo com Dejours, constituem mecanismo de proteção e adaptação. Em alguns casos, pode se configurar um tipo específico, as defesas de exploração, que se relacionam com o mecanismo de defesa do ego de submissão (Mendes, 2007).

A relação saúde-doença-trabalho para a Psicodinâmica do Trabalho (PdT) é, então, estabelecida a partir da relação de um trabalhador com seus pares, mediado pela relação daquele com o real do trabalho, de forma a mobilizar seus recursos individuais e/ou coletivos e através do qual se espera uma retribuição, que pode ser financeira, mas que além de tudo é moral e simbólica (Merlo, 2014). O reconhecimento representa a retribuição após o engajamento de si no trabalho e tem papel central no fortalecimento da identidade, sendo, desta forma, capaz de transformar os afetos mobilizados no encontro do trabalhador com o real do trabalho, podendo constituir-se como principal armadura da saúde mental dos trabalhadores (Dejours \& Bègue, 2010).

Assim, pela perspectiva dejouriana, se o trabalho pode levar ao adoecimento, à degradação da saúde mental, ele também é capaz de, ao contrário, proporcionar o melhor: muitos homens e mulheres estão em melhor estado de saúde mental do que estariam caso não trabalhassem (Dejours, 1992). Encontramo-nos, então, nesse dilema: valorizar, de um lado, o trabalho como espaço privilegiado de inscrição humana na vida social e de produção de sua subjetividade e prazer; de outro, reconhecer que a experiência concreta que se vive no trabalho conduz, muitas vezes, ao sofrimento e adoecimento. Desta forma, elucidar as condições em que o trabalho seja mediador de saúde ou produtor de doença é necessário para que as práticas possam evoluir no campo da proteção da saúde no universo de trabalho, em especial, nesta pesquisa à proteção da saúde do trabalhador prisional. Assim, o objetivo desta pesquisa foi compreender os aspectos da organização do trabalho que contribuem para a vivência de sofrimento e/ou prazer dos inspetores penitenciários capixabas e, logo, as estratégias defensivas postas em ação por estes trabalhadores.

\section{Procedimentos metodológicos}

Esta pesquisa foi realizada baseada na metodologia da Psicodinâmica do Trabalho (Dejours, 1992). Para execução desta investigação, seguiram-se as seguintes etapas descritas pelo autor: a pré-pesquisa, a pesquisa propriamente dita, análise e interpretação do conteúdo e validação. Algumas adaptações metodológicas foram realizadas para a execução da pesquisa, que serão explicadas a seguir.

\section{A Pré-Pesquisa}

A demanda é o ponto de partida da PdT, nesta pesquisa, a mesma se constituiu de maneira informal, através das solicitações registradas nas capacitações dos profissionais. O segundo passo configurou-se pela busca de informações sobre o trabalho dos profissionais inspetores e seu processo histórico, sua transformação ou mutações: processo de admissão (formas de ingresso), número de profissionais em cada tipo de contratação, dados sobre a categoria (portarias e padrões operacionais, afastamento, licenças).

\section{Participantes}

Os participantes da pesquisa foram 19 inspetores penitenciários, de um total de 3.146, sendo 1954 servidores efetivos e 1192 contratados em designação temporária, todos do sexo masculino, lotados em cinco unidades prisionais da grande Vitória, contemplando-se tanto unidades em modalidade de regime de triagem, quanto provisório e fechado. O método de seleção dos participantes se deu por conveniência, para definição da quantidade de participantes, após cada grupo de 
entrevistas, procedia-se uma prévia categorização dos principais temas abordados, conforme os comentários registrados em sequência, o que auxiliou na conformidade quanto à quantidade de participantes.

Do total dos 19 entrevistados individualmente 14 são concursados e cinco são contratados em designação temporária (DT). Destes, 17 trabalham em regime de escala $24 / 72$ horas e dois em regime de escala $4 \times 4$ (quatro dias em expediente administrativo e quatro dias de folga). Nove relataram ter ensino superior completo ou incompleto, sendo que destes, apenas um é DT. A média ( $M$ ) de tempo de serviço (ts) e de idade é maior no grupo de DT ( $M=40$ anos; $M t s=7$ anos), em relação aos concursados, $(M=32 ;$ Mts $=5$ anos $)$.

\section{A Pesquisa}

A pesquisa foi realizada, mediante a assinatura do Termo de Consentimento Livre e Esclarecido, como também previamente aprovada pelo "Comitê de Ética em Pesquisa em Psicologia da Universidade Federal do Espírito Santo". A pesquisa propriamente dita consistiu de sete visitas às três unidades prisionais (as primeiras para a apresentação da pesquisa e registro das observações gerais) das 17 unidades do Estado, que culminaram em 19 entrevistas individuais, realizadas em sala de atendimento da psicologia, registradas mediante uso de gravador digital. A metodologia original da PdT prevê um espaço de discussão pública, no local de trabalho, onde os trabalhadores possam falar, individualmente ou em grupo, sobre a organização do trabalho (Dejours, 1992; Mendes, 2007). Desta forma, após o consentimento, a Instituição direcionou as Unidades que estariam interessadas em receber e participar desta presente pesquisa. Em média, as entrevistas, que se basearam em elenco de questões semiestruturadas constituídas mediante orientações da PdT (Mendes \& Araújo, 2011). O roteiro da entrevista se orientou por questões mobilizadoras referentes aos Eixos: organização do trabalho e condições de trabalho (abordando temas como o que se faz no trabaIho, as condições e dificuldades encontradas); mobilização subjetiva (sobre temas como as estratégias utilizadas para enfrentar as dificuldades, as relações entre pares, hierarquia e instituição, e o fenômeno da prisionização) e sofrimento, defesas e estratégias defensivas (abarcando temas como identidade profissional, sentimento sobre o trabalho, o sindicato, valorização e reconhecimento).

\section{A Análise}

A análise foi iniciada desde o momento do registro dos comentários do pesquisador. E a partir das transcrições do material gravado foi realizado o método de interpretação do conteúdo de Bardin (1994). A sequência de análise se deu da seguinte forma: (I) classificação individualizada das entrevistas, sem previsão de qualquer relação com a PdT, sem classificá-las a priori nas categorias ou eixos previstos por essa teoria; (II) agrupamento das sínteses que se repetiam, padronizando-as, enumerando-as conforme seu teor significativo; (III) análise das sínteses e a possível correlação com a PdT, gerando a inclusão das sínteses em categorias e eixos conforme a PdT; (IV) organização da categorização, obedecendo a seguinte sequência e numeração: eixo (1, 2 ou 3) - categoria (que varia de acordo com o eixo) identificação do entrevistado (que varia de 1-19) - síntese temática correspondente.

A classificação dos dados e organização dos eixos foi inspirada pela metodologia da PdT (Dejours, 1992) e obedeceu ao proposto por Mendes e Araújo (2011), descritos na tabela 1.

Tabela 1. Descrição dos Eixos PdT

\begin{tabular}{|c|c|}
\hline Eixo & Conteúdo, Descrição \\
\hline $\begin{array}{l}\text { Organização do } \\
\text { Trabalho e Condição } \\
\text { de Trabalho }\end{array}$ & $\begin{array}{l}\text { Conteúdo e descrição das tarefas, normas e } \\
\text { controle; tempo e ritmos, comunicação, relações } \\
\text { de trabalho entre os pares, a hierarquia, a } \\
\text { instituição e modos de gestão; ambiente } \\
\text { físico, ambiente químico, ambiente biológico, } \\
\text { as condições de higiene e segurança, e as } \\
\text { características antropométricas do posto de } \\
\text { trabalho. }\end{array}$ \\
\hline $\begin{array}{l}\text { Mobilização } \\
\text { Subjetiva }\end{array}$ & $\begin{array}{l}\text { Inteligência prática e criativa, reconhecimento, } \\
\text { cooperação, espaço público de discussão. }\end{array}$ \\
\hline $\begin{array}{l}\text { Sofrimento, Defesas } \\
\text { e Estratégias }\end{array}$ & $\begin{array}{l}\text { Sofrimento, defesas e estratégias: sofrimento } \\
\text { criativo, sofrimento patogênico; defesas; } \\
\text { patologias; danos físicos e psicossociais. }\end{array}$ \\
\hline
\end{tabular}

\section{A Validação}

A validação foi realizada mediante a realização da própria pesquisa através das elaborações, interpretações, hipóteses, temas e comentários registrados após cada entrevista (Dejours, 1992).

\section{A organização do trabalho prisional e as vivências de prazer e sofrimento}

Após a interpretação do conteúdo discursivo apresentado pelos participantes iniciou-se a análise que culminou na classificação dos dados em eixos, categorias e sínteses, apresentados a seguir pela tabela 2, 3 e 4, tendo como objetivo elencar aspectos da organização do trabalho que contribuem para a vivência de prazer e/ ou sofrimento, como também, identificar as estratégias defensivas produzidas. 
Tabela 2. Resultados Eixo 1 - Organização do Trabalho (OT) e Condições do Trabalho (CT)

\begin{tabular}{|c|c|}
\hline Categoria & Síntese \\
\hline \multirow{6}{*}{$\begin{array}{l}\text { Categoria } 1 \text { (CT) } \\
\text { Ambiente físico e características } \\
\text { antropométricas e psicológicas do Posto } \\
\text { de Trabalho }\end{array}$} & 1: ambiente de trabalho insalubre, quente e barulhento \\
\hline & 2: instrumentos de trabalho insuficientes e sem manutenção \\
\hline & 3: sobrecarga de trabalho \\
\hline & 4: alojamento e locais de descanso em condições precárias \\
\hline & 5: equipamentos de Segurança insuficientes e precários \\
\hline & 6: ambiente tenso, negativo \\
\hline \multirow{5}{*}{$\begin{array}{l}\text { Categoria } 2 \text { (OT) } \\
\text { Rotina e Divisão do Trabalho }\end{array}$} & 1: Funções gerais do Inspetor Penitenciário \\
\hline & 2: Revezamento recorrente de postos de trabalho \\
\hline & 3: Diferentes tipos de contrato - diferentes tipos de atividade e status \\
\hline & 4: Constrangimentos da tarefa - banho de sol e escolta \\
\hline & 5: Constrangimentos das tarefas - procedimento de revista e movimentação de presos \\
\hline \multirow{6}{*}{$\begin{array}{l}\text { Categoria } 3 \text { (OT) } \\
\text { Gestão, Suporte Organizacional, } \\
\text { categoria e coletivo }\end{array}$} & 1: Política de promoção por apadrinhamento e não meritocracia \\
\hline & 2: Chefia despreparada, autoritária e militarista - assédio moral \\
\hline & 3: Instituição não oferece suporte e respaldo para o cumprimento das normas e regras \\
\hline & 4: Imagens - do coletivo ao individual "Torturadores e Corruptos" \\
\hline & 5: Sindicato não representativo, fragilizado e desacreditado \\
\hline & 6: Desunião da categoria, individualismo \\
\hline
\end{tabular}

Tabela 3. Resultados Eixo 2 - Mobilizações Subjetivas

\begin{tabular}{ll}
\hline \multicolumn{1}{c}{ Categoria } & \multicolumn{1}{c}{ Síntese } \\
\hline Categoria 1 & 1: Eficácia e eficiência - inteligência prática e criativa \\
Mobilizações da Inteligência & 2: Desapego ao prescrito \\
& 3: Uso de Macetes coletivos - regras de contato com o preso \\
& 1: Não reconhecimento pelos superiores x reconhecimento entre os pares \\
Categoria 2 & 2: Sentido do trabalho - repressor da criminalidade (antipatia ao preso) x Ressocializador (simpatia ao preso) \\
Mobilizações da Personalidade & 3: Cooperação em subgrupos x individualismo e promoção pessoal \\
& 4: Identificação com a tarefa - amor a camisa \\
\hline
\end{tabular}

Tabela 4. Resultados Eixo 3 - Vivência de Sofrimento e Prazer

\begin{tabular}{|c|c|}
\hline Categoria & Síntese \\
\hline \multirow{7}{*}{$\begin{array}{l}\text { Categoria } 1 \\
\text { Danos Físicos e } \\
\text { Psicossociais }\end{array}$} & 1: Restrição e interferência na rotina e nos hábitos no tempo fora do trabalho \\
\hline & 2: Reprodução de gestos e atitudes do trabalho no tempo fora do trabalho \\
\hline & 3: Estado de tensão e alerta permanente - desconfiança/paranoia \\
\hline & 4: Perturbação do sono \\
\hline & 5: Ansiedade \\
\hline & 6: Medo \\
\hline & 7: Estresse \\
\hline \multirow{4}{*}{$\begin{array}{l}\text { Categoria } 2 \\
\text { Estratégias e Defesas }\end{array}$} & 1: Estratégias - não criar expectativas (conformismo) ou superá-las (servidão voluntária) \\
\hline & 2: Ideologia defensiva - 2.1. Contorno do risco; 2.2. Aceitação do risco; 2.3. Minimização do risco \\
\hline & 3: Envolvimento afetivo/amoroso \\
\hline & 4: Afastamento do trabalho \\
\hline \multirow{4}{*}{$\begin{array}{l}\text { Categoria } 3 \\
\text { Sofrimento Patogênico }\end{array}$} & 1: Exploração, humilhação \\
\hline & 2: Insatisfação \\
\hline & 3: Angústia \\
\hline & 4: Sentimento de impotência \\
\hline \multirow{4}{*}{$\begin{array}{l}\text { Categoria } 4 \\
\text { Sofrimento Criativo }\end{array}$} & 1: Orgulho da profissão \\
\hline & 2: Satisfação \\
\hline & 3: Tempo fora do trabalho valorizado - lazer não envolvendo o trabalho \\
\hline & 4: Entusiasmo \\
\hline
\end{tabular}


Dentre os resultados observados verifica-se que o cenário do sistema prisional capixaba, mesmo com todas as peculiaridades, não difere do quadro nacional, apontado em outras pesquisas (Rumin et al., 2011; Santos, 2010; Tschiedel \& Monteiro, 2013; Vasconcelos, 2000). As condições de trabalho também foram consideradas precárias no que concerne ao ambiente insalubre e a poucos recursos de higiene e equipamentos, à submissão, à sobrecarga de trabalho, ao risco de contaminação por meio de agentes biológicos e ao estado de tensão frente aos perigos inerentes a profissão.

Os participantes chegaram a destacar melhoria na estrutura das unidades prisionais, configurando uma modernização do ambiente em comparação com o quadro de degradação vivenciado no passado. Porém, mesmo diante dessa percepção, esse ambiente ainda se configura aos trabalhadores como insalubre, tanto pela própria arquitetura, quanto por sua dinâmica própria: "nessa parte aí o Estado é zero (condições de trabalho) (...) a estrutura desses presídios não são boas, né, são parte metálica, pode ser que você está caminhando ali, e de repente o negócio cai" (trecho entrevistado 12).

De forma geral, o modo de gestão demarcado pela prática de dois tipos de contrato (efetivo ou DT), define, entre outros a divisão de tarefas e o porte de arma, o que institui diferente grau de contato - mais ou menos próximos - que se terá com o detento. São os DTs que atuam mais diretamente com os presidiários. O contrato define também tipos de escala de trabalho, diferenças financeiras, e intensidades distintas de carga de trabalho, "a divisão de trabalho de todos os agentes, quem é armado sempre trabalha com o armado (efetivo), quem é o pessoal do DT, ficam mais na parte da movimentação, que os armados já ficam responsáveis pela segurança da unidade" (trecho entrevistado 5).

Tais distinções de contrato produzem consequentemente diferentes vivências profissionais, com efeitos subjetivos, entre outros, na identidade profissional. Por exemplo: o fato de ser negada a determinada parcela de trabalhadores o uso de alguns instrumentos (como porte de arma e outros equipamentos letais) e determinado poder de ação, confere-Ihes um discurso e sentimento de menos-valia. Gaulejac (2006) evidencia como os modos de gestão atuais têm contribuído para a degradação do trabalho, ao invés de melhorar as relações humanas, desmotiva o trabalhador e contribui para a deterioração e aniquilamento do coletivo de trabalho. As diferentes formas de contrato para a execução da mesma atividade podem conferir, ainda, maior ou menor status ao profissional (Perissé, 2012).

\section{Diferenças de Contrato e o Coletivo de Trabalho}

A desarticulação do coletivo desestabiliza as relações de trabalho de forma a impossibilitar as transformações que poderiam ser convertidas em qualidade e melhorias nas condições do trabalho. Essa condição não parece restrita ao contexto prisional, evidências sobre a desarticulação do coletivo em virtude das diferentes formas de contrato foram apontadas na pesquisa com profissionais da informática (Martins, 2012). Nestas condições, o coletivo, que segundo Moraes e Atayde (2014, p. 333), deveria "auxiliar, a cada um do grupo como um todo, a enfrentar os imprevistos do trabalho que emergem em cada atividade, em todas as suas dimensões (linguageira, organizacional, social, instrumental, desenvolvimental, entre outras)", parece cumprir apenas em parte sua função para esta categoria.

Acho desunida a categoria, tem muitos agentes que, por ser efetivo, andar armado, acha que é o rei da cocada preta, não pode ajudar a pagar a marmita, não pode fazer certas coisas porque é efetivo e às vezes sobra tudo pro DT (trecho entrevistado 18).

Ainda que na tradição da PdT não haja uma relação imediata entre coletivo de trabalho e organização sindical, embora a base para tais dimensões seja sempre a atividade de trabalho, pode-se observar que a des-coletivização dos inspetores penitenciários, por assim dizer, repercute de maneira intensa também nas lutas sindicais e na constituição da categoria, o que leva a uma Instituição Sindical deslegitimada: "eles querem fazer greve; eu, como DT, igual você sabe (...), eu posso ir lá fazer greve? Não posso. Se eu for lá fazer greve mês que vem, semana que vem eles já me mandam embora" (trecho entrevistado 15).

\section{Coletivo, Reconhecimento e Sentido}

O coletivo do trabalho enfraquecido também dificulta a psicodinâmica do reconhecimento, que poderia se configurar como antídoto para o processo de adoecimento e antitrasnformação, "falta de reconhecimento eu acho que é a maior dificuldade (...), às vezes você também quer ver pelo menos um elogio, né" (trecho entrevistado 12). O não reconhecimento tem se convertido em sofrimento para os trabalhadores (Augusto, Freitas, \& Mendes, 2014; Santos, 2010; Sousa \& Mendonça, 2009). Assim a qualidade do 
reconhecimento, possibilitada através das relações, horizontais e verticais, que viabilizará a comutação do sofrimento e a ativação das mobilizações subjetivas como a cooperação e outras estratégias defensivas.

Outro aspecto significativo influenciado pela desarticulação do coletivo é a não produção de consenso quanto ao sentido atribuído ao trabalho, já que este coletivo não parece ser suficiente para solidificar as exigências mínimas de confiança para um espaço público de julgamentos e trocas. Isso contribui também para a construção de uma identidade profissional ambígua, ora permeada pela identificação com as forças de segurança policial "eu não gosto de preso, (...) me ira muito quando eu vejo um cara fazendo hora com a minha cara" (trecho entrevistado 6), ora por seu papel no processo de reintegração social "um elo entre o preso, sim, e todos os setores que vão concorrer pra que ele venha ingressar na sociedade melhor, eu não quero chegar aqui e contribuir pra que o cara volte pra sociedade pior do que ele entrou" (trecho entrevistado 11).

O sentido do trabalho (ou a perda de sentido), parte da psicodinâmica do trabalho, tem relação crucial para o acesso à identidade, juntamente com a realização de si mesmo, sendo "central na construção da saúde mental e física" (Dejours 2011, p. 446). A dimensão social, de acordo com Morin (2002), constitui parte inegável como contribuição ao sentido ao trabalho. Portanto, quando existem sentidos dúbios em relação ao trabalho e, consequentemente em relação à identidade profissional, o trabalhador, em algum momento, pode se deparar com a perda total do sentido: "eu não sei dizer porque a gente mantém preso (...) Se eu procurar o sentido do meu trabalho...(...) eu venho, trabaIho, recebo meu salário, mas eu não sei o quê que eu tô fazendo aqui" (trecho entrevistado 4 - efetivo). Essa substancial perda de sentido, em meio à ambivalência quanto à identidade profissional, alerta para o quão desestruturante pode ser um trabalho sem sentido, caso não consigam mobilizar suas estratégias e defesas.

\section{Sofrimento, Medo e Trabalho}

O sofrimento, que na perspectiva da PdT (Dejours, 2011) pode ser patogênico ou criativo, então, também é atravessado pela lógica dos diferentes contratos, status e escalas de trabalho. Objetivamente foram descritos como uma série de efeitos ou "danos físicos e psicossociais" advindos da organização e condições do trabalho. Dentre eles a perturbação do sono, ansiedade, medo, estresse e comportamentos antissociais: "meu sono é péssimo, tanto aqui quanto em casa. Eu já acordei sonhando que tinham me matado, que tava aqui dentro e o troço começou a...péssimo, né?" (trecho entrevistado 2). De forma geral foram descritos como algo implícito ao trabalho e percebidos pelos participantes, tanto efetivos quanto DT.

A vivência de medo, por exemplo, como parte dos danos 'físicos e psicossociais', se configura em alguns momentos na preocupação em evitar fugas "no momento que a gente tá conversando eu não sei o quê que o preso tá fazendo lá dentro, não sei se ele pode tá querendo fugir" (trecho entrevistado 11), conforme visto também em outras pesquisas (Lourenço, 2010; Vasconcelos, 2000; Zaffaroni, 1991).

Nesta pesquisa, porém, outro aspecto do medo foi destacado: o medo de morrer ou ser ferido pelos presos em confrontos dentro ou fora do trabalho. O medo, quase sempre ignorado como aspecto concreto da realidade (Dejours, 1992), exige sistemas defensivos específicos. Ao surgir nas verbalizações, ao mesmo tempo em que é visto como algo inerente à função, é percebido como evitável através de regras de conduta e convivência e regulação de hábitos e lugares a se frequentar: "eu acredito, ninguém morre à toa, toda ação tem uma reação(...) e depende do modo de trabalhar da pessoa, claro que...e os locais que frequentam, né?"(trecho entrevistado 17); ou do empoderamento por meio de atitudes narcísicas de virilidade e superpoder "(...) vagabundo não é burro, eles não vão bater de frente com o Estado de jeito nenhum, eles se matam lá, mas não querem confusão com o Estado porque sabem que os caras [inspetores] são doido" (trecho entrevistado 16).

\section{Defesas, Sofrimento Negativo e Sofrimento Positivo}

Apesar das condições precárias e do medo, observou-se nessa e em outras pesquisas (Sousa \& Mendonça, 2009; Tschiedel \& Monteiro, 2013) alguma satisfação dos trabalhadores com determinados aspectos da organização do trabalho e, em alguns casos, a manifestação do sofrimento criativo, possibilitado pelo engajamento da criatividade e astúcia. A criatividade para driblar a falta de autonomia e a tensão do meio de trabalho é apresentada por alguns participantes e demonstra indícios de ressignificação do sofrimento:

os caras até brincam comigo as vezes que eu trabaIho de boina e tal, faço uma barba diferente e tal porque eu gosto, eu venho aqui e me entrego ao serviço, e criei eu acho que meu modo de trabaIhar (trecho entrevistado 8). 
Mendes e Araújo (2011) enfatizam o papel da mobilização subjetiva (ou sua ausência) no adoecimento, como movimento do sujeito na busca pela transformação das contradições e dramas reais em sofrimento criativo. A mobilização de diferentes estratégias defensivas foi identificada, porém individualmente. No caso da ausência do reconhecimento, movimentos distintos foram descritos. Para os inspetores DT, o sentido do reconhecimento é reapropriado: 'ser reconhecido' então, caracteriza-se pela gratidão frente à instituição pela permanência no trabalho, visto como forma de retribuição: "'sempre alguém te olha', a minha trajetória no sistema penitenciário, eu tô até hoje porque alguém reconheceu meu trabalho,...é...hoje eu tô aqui devido ao mérito do meu trabalho"(trecho entrevistado 17 - inspetor penitenciário DT). Neste sentido, o trabaIhador parece utilizar de ação para subverter tal situação, numa atitude de reapropriação, que para Dejours (1999) trata-se de um processo pelo qual o sujeito não fica passivo diante das contradições do trabalho e cria formas para utilizar o trabalho para sua autorrealização. Contudo, tal ação pode chegar a uma atitude servil, encaminhando-o para uma patologia da servidão, que se caracteriza como atitude de submissão subjetiva do trabalhador, num processo de servidão, a qual adere para manter seu emprego ou ser promovido (Mendes, 2007). Para tanto, muitas vezes abstêm-se de suas opiniões e valores, mostrando-se feliz e satisfeito, quando de fato vivencia o sofrimento e a insatisfação (Carvalho \& Moraes, 2011).

Diante da fragilidade do vínculo, o inspetor DT demonstra estar vulnerável a este tipo de estratégia defensiva, já que para manter o emprego, necessita de "mostrar serviço": "então o chefe de equipe vai ver em você o quê? Ela tem disposição, ela trabalha em qualquer lugar que manda e nunca reclama (...). Essa é uma questão que o chefe vai ver 'Não, ela tá sempre à disposição" (trecho entrevistado 15 - grifo nosso).

A servidão voluntária parece fazer frente às questões relativas, por exemplo, aos níveis diferenciados de divisão das tarefas, quanto ao porte negado, como também, para manter-se no trabalho e contra o sofrimento patogênico, como também demonstrado por Martins (2012) em pesquisa com trabalhadores da informática concursados e terceirizados. Nesse sentido, esse tipo de defesa é descrita por Dejours como bivalente, no caso do sofrimento, pois dar conta dele significa, de certa forma, conservar a organização de trabalho, em lugar de transformá-la, num processo denominado por "antitransformação" (Dejours 2011, p. 174).
No outro extremo, para alguns inspetores efetivos, a ausência de reconhecimento hierárquico é substituída, em algumas situações, pelo reconhecimento originado dos pares, ou seja, horizontal ou estético (pares do mesmo grupo - efetivo). Este reconhecimento, descrito por alguns participantes, é evidenciado como algo substancial e positivo: "eu conserto algema e os PD140 também, descobri que eu conseguia consertar, (...) então eu fico feliz quando um colega liga e fala "Bicho, eu tô na merda aqui" (trecho entrevistado 16).

A despeito desses esforços de comutar o sofrimento em sofrimento criativo, infelizmente, conforme Mendes e Araújo (2011), nem sempre a presença das mobilizações é possibilitada, e o adoecimento acaba sendo única via para o real. O trabalho prisional, por tudo que foi apresentado, não viabiliza facilmente a produção de outras lógicas de sofrimento, que não a patogênica, confluindo para efeitos psicossociais preocupantes. Em contrapartida, nem todo sofrimento se configura em adoecimento e mesmo o adoecimento não constitui ausência de esforço para se recobrar a produção de saúde:

já não tenho dado tanta conta, até porque eu fui afastado 15 dias pela psiquiatra, ainda vou ter uma nova consulta, (...) é... tentei de alguma forma, algum tipo de estratégia pra tolerar, pra tipo... eu sair do meu corpo (trecho entrevistado 7),

até porque o conceito de doença, a partir da leitura psicanalítica, "pode significar saúde e vice-versa" (Brant \& Minayo-Gomez, 2004, p. 221).

Seguindo a $\mathrm{PdT}$, seria uma preocupação inútil discutir em que condições ou sob quais condições são mobilizadas as inteligências ou as personalidades. Segundo Dejours (2011), o que importa é saber como não quebrar as mobilizações, ou seja, como não impossibilitar o uso das estratégias defensivas,

se eu fosse uma pessoa que não trabalhasse nisso aqui, eu poderia frequentar normal, só que o quê que acontece: você vem aqui e você olha pra três, quatro presos que são os xerifes lá do morro tal, como é que você vai lá? (trecho entrevistado 2).

Assim, "evitar frequentar a periferia" se constitui como estratégia defensiva contra o medo referente às tentativas de homicídio, na medida em que a criminalidade está, para os trabalhadores, localizada geograficamente. Contudo, diante desta realidade, quando esta via é interrompida por alguma razão, e não há engajamento de outros recursos e estratégias, o que 
se percebe é a vivência de sofrimento patogênico: "eu, particularmente, sou um que preciso procurar um psicólogo, um psiquiatra para poder assim... 'oh, me tira disso aqui um tempo porque eu não estou aguentando mais'" (trecho entrevistado 2).

Em conclusão, nesta pesquisa, verificou-se que as condições de trabalho, ainda que melhores que em outros momentos, são ainda precárias, principalmente em relação à higiene, equipamentos e recursos humanos, conforme tabela 2, o que contribui para um espaço insalubre e sobrecarga de trabalho. Somam-se a isso os diferentes tipos de contrato, como também as diversas escalas de trabalho, que convergem para o agravamento destas condições, já que, sobretudo, prejudica a consolidação do coletivo profissional e em consequência impede estruturação de defesas coletivas, como a cooperação, reconhecimento e partilha das mobilizações subjetivas. O que implica, além de tudo, na dificuldade da constituição da identidade e sentido atribuído à profissão, essencial para proteção e armadura da saúde mental.

No que se refere às vivências de prazer, percebe-se que se estes trabalhadores "respeitam parcialmente os indivíduos do coletivo, o mesmo não ocorre nos coletivos específicos para a luta contra a organização do trabalho" (Dejours, 2011, p. 180). Resulta daí que as vivências individuais de ressignificação do sofrimento, que se dão ao que parece, pela via do desejo (sublimatório), "não são, segundo a proposta desta abordagem, passíveis de coletivização" (Dejours, 2011, p. 180). Desta maneira, conclui-se que, para a transformação deste espaço e das condições de trabalho, as relações entre trabalhador-organização têm de ser modificadas, no sentido de ampliar o diálogo e legitimar o saber-fazer do trabalhador, como também garantir condições idênticas de trabalho, pelo menos no que tange ao contrato, contribuindo, inclusive, para a recomposição do coletivo de trabalho e assim, para a partilha das defesas coletivas, tão essenciais às vivencias do prazer.

\section{Considerações finais}

O estudo permitiu uma melhor compreensão da subjetividade impressa no trabalho dos inspetores penitenciários. Como as vivências de prazer não foram percebidas de forma coletiva fica evidente que estas estratégias não se apresentam como suficientes para a manutenção e proteção da saúde mental. Ainda há necessidade de realização de mais pesquisas, sobretudo as de caráter de pesquisa intervenção, para que estas se constituam meios legítimos de transformação dos ambientes de trabalho. A sugestão, apontada nesta pesquisa é o fortalecimento do coletivo do trabalho, mediante modos de gestão mais participativos e formas de ingresso que garantam as mesmas condições trabalhistas, para que outras vias de ressignificação do sofrimento e vivência do prazer sejam oportunizados.

\section{Referências}

Arendt, H. (2016). A condição humana (13 $3^{\text {a }}$ ed.). Rio de Janeiro: Forense Universitária.

Augusto, M., Freitas, L., \& Mendes, A. (2014). Vivências de prazer e sofrimento no trabalho de profissionais de uma fundação pública de pesquisa. Psicologia em Revista, 20(1), 34-55. doi: 10.5752/P.1678-9523.2014v20n1p34.

Bardin, L. (1994). Análise de conteúdo. Lisboa: Edições Setenta.

Brant, L., \& Minayo-Gomez, C. (2004). A transformação do sofrimento em adoecimento: do nascimento da clínica à psicodinâmica do trabalho. Ciência \& Saúde Coletiva, 9(1), 213-223. doi: 10.1590/ S1413-81232004000100021

Carvalho, G. M., \& Moraes, R. D. (2011). Sobrecarga de trabalho e adoecimento no polo industrial de Manaus. Psicologia em Revista, 17(3), 465-482. doi: 10.5752/P.1678-9563.2011V17N3P465

Dejours, C. (1992). A loucura do trabalho: estudo de psicopatologia do trabalho ( $5^{\mathrm{a}}$ ed.) São Paulo: Cortez-Oboré.

Dejours, C. (1999). Conferências brasileiras: identidade, reconhecimento e transgressão no trabalho (A. C. F. Reis, Trad.; M. I. S. Betiol \& M. J. Tonelli, Rev. Técn.). São Paulo: Fundap. EAESP/FGV.

Dejours, C. (2003). O fator humano (4ª ed.). Rio de Janeiro: Editora FGV.

Dejours, C. (2011). Addendum: da psicopatologia à psicodinâmica do trabalho. In S. Lancman \& L. I. Sznelwar (Orgs.), Christophe Dejours: da psicopatologia à psicodinâmica do trabalho (pp. 47-104). Rio de Janeiro/Brasília: Fiocruz/Paralelo 15.

Dejours, C., Abdouchelli, E., \& Jayet, C. (1994). Psicodinâmica do Trabalho - contribuições da escola Dejouriana à análise do prazer, sofrimento e trabalho. São Paulo: Atlas.

Dejours, C., Barros, J., \& Lancman, S. (2016). A centralidade do trabaIho para a construção da saúde. Revista de Terapia Ocupacional da Universidade de São Paulo, 27(2), 228-235. doi: 10.11606/ issn.2238-6149.v27i2p228-235

Dejours, C., \& Bègue, F. (2010). Suicídio e trabalho: o que fazer? Brasília: Paralelo 15.

Finney, C., Stergiopoulos, E., Hensel, J., Bonato, S., \& Dewa, S. C. (2013). Organizational stressors associated with job stress and burnout in correctional officers: a systematic review. Biomed Central Public Health, 13(82), 1471-2458. doi: 10.1186/1471-2458-13-82

França, D. (2011). A satisfação no trabalho dos agentes penitenciários do Complexo Médico Penal do Estado do Paraná (Dissertação de pós-graduação). Recuperado de http://dspace.c3sl.ufpr.br:8080/ dspace/bitstream/handle/1884/33704/DARLEY\%20FRANCA. pdf?sequence $=1$

Garcia, L. (2008). Uma análise sobre a mortalidade de inspetores penitenciários do Rio de Janeiro entre 1994-2006. (Dissertação de 
A organização do trabalho prisional e as vivências de prazer e sofrimento

Especialização Leituras em Violência, Escola Nacional de Saúde Pública). Fundação Oswaldo Cruz, Rio de Janeiro.

Gaulejac, V. (2006). Gestão como doença social. São Paulo: Ideias e Letras.

Goffman, E. (2013). Manicômios, prisões e conventos (5 ed.) São Paulo: Perspectiva.

Ministério da Justiça (2014): Departamento Penitenciário Nacional. Levantamento Nacional de informações Penitenciárias Infopen. Brasília, DF: Ministério da Justiça.

Konda, S., Reichard, A. A., \& Tiesman, H. M. (2012). Occupational injuries among U.S. correctional officers. Journal of Safety Research, 43(3):181-6. doi: 10.1016\%2Fj.jsr.2012.06.002

Lopes, R. (2002). O cotidiano da violência: o trabalho do agente de segurança penitenciária nas instituições prisionais. Psicologia para América Latina, 1, 15-22. Recuperado de http://psicolatina.org/Uno/ psicologia_juridica.html

Lourenço, L. C. (2010). Batendo a tranca: impactos do encarceramento em agentes penitenciários da Região Metropolitana de Belo Horizonte. Revista de Estudos de Conflito e Controle Social, 13(10), 11-31. Recuperado de https://revistas.ufrj.br/index.php/dilemas/ article/view/7181

Martins, M. (2012). A psicodinâmica do reconhecimento no trabalho de informática de terceirizados e concursados de uma instituição pública (Dissertação de mestrado). Recuperado de http://bd.camara.gov.br/bd/handle/bdcamara/13236

Mendes, A. M. (Org.). (2007). Psicodinâmica do trabalho: teoria, método, pesquisas (1 $1^{a}$ ed.) São Paulo: Casa do Psicólogo.

Mendes, A, M., \& Araújo, L. K. R. (2011). Clínica psicodinâmica do trabalho: práticas brasileiras. Brasília: Ex. Libris.

Merlo, A. R. C. (2014). Processo de globalização, sofrimento psíquico e atenção à saúde mental no trabalho. In A. M. Mendes, R. D. Moraes, \& A. R. C. Merlo (Orgs), Trabalho e Sofrimento - Práticas Clínicas e Políticas (pp. 25-35). Curitiba: Juruá.

Moraes, T. D., \& Atayde, M. R. C. (2014). Dimensões do coletivo na atividade de trabalho dos motoboys. Fractal: Revista de Psicologia, 26(2), 327-348. doi: 10.1590/1984-0292/906

Morin, E. (2002). Os sentidos do trabalho. In T. Wood (Org.), Gestão empresarial: o fator humano (pp. 13-34). São Paulo, SP: Atlas.

Perfil Profissiográfico da função de Agente Penitenciário. (2004). Poder Executivo. Publicado no Diário Oficial no 6653. Recuperado de http://www.portaldoservidor.pr.gov.br/arquivos/File/antigos/74/perfil_profis_ag_penit_res_3027_2004.pdf

Perissé, N. B. (2012). "As pessoas já entram se sentindo menores": impactos da terceirização na subjetividade do trabalhador
(Dissertação de mestrado). Recuperado de http://www.bdtd.ndc.uff. br/tde_busca/processaPesquisa.php?pesqExecutada $=1 \& \mathrm{id}=3146$

Rumin, C. R., Barros, G. I. F., Cardozo, W. R., Cavalhero, R., \& Atelli, R. (2011). O sofrimento psíquico no trabalho de vigilância em prisões. Psicologia: Ciência e Profissão, 31(1), 188-199. doi: 10.1590/ S1414-98932011000100016

Santos, M. M. (2010). Agente penitenciário: trabalho no cárcere (Dissertação de Mestrado). Recuperado de http://repositorio.ufrn. br/jspui/handle/123456789/17464

Schwartz, Y. (2000). Trabalho e uso de si. Revista Pró-Posições, 11(2), 34-50. Recuperado de https://periodicos.sbu.unicamp.br/ojs/index. php/proposic/article/view/8644041

Secretaria de Estado da Justiça/ES - SEJUS. (s.d.). Missão e visão. Vitória: SEJUS. Recuperado de http://www.sejus.es.gov.br/index. php/missao-visao-e-valores.

Secretaria de Estado da Justiça/ES - SEJUS. (2013). Sistema penitenciário capixaba: relatório - fevereiro/2013. Vitória: SEJUS. Recuperado de www.sejus.es.gov.br/download/relatorio_fevereiro2013.pdf

Secretaria de Estado da Justiça/ES - SEJUS. (2015). Informações penitenciárias do Espírito Santo. Recuperado de http://www.cnj.jus.br/ files/conteudo/arquivo/2015/10/6e84a9b61e4a2da443a685be6b23afd2.pdf

Sousa, I. A. C. M. O., \& Mendonça, H. (2009). Justiça organizacional, prazer e sofrimento no trabalho: análise de um modelo mediacional. Revista de Administração Mackenzie, 10(4), 57-74. doi: 10.1590/ S1678-69712009000400004

Thompson, A. (2002). A questão penitenciária (5⿳⺈⿴囗十一 ed.). Rio de Janeiro: Forense.

Tschiedel, R., \& Monteiro, J. (2013). Prazer e sofrimento no trabalho das agentes de segurança penitenciária. Estudos de Psicologia, 18(3), 527-535. doi: 10.1590/S1413-294X2013000300013

Varella, D. (2012). Carcereiros. São Paulo: Companhia das Letras.

Vasconcelos, A. S. F. (2000). A saúde sob custódia: um estudo sobre agentes de segurança penitenciária no Rio de Janeiro (Dissertação de mestrado). Recuperado de http://arca.icict.fiocruz.br/handle/ icict $/ 5181$

Zackseski, C, Machado, B. A., \& Azevedo, G. (2016). Dimensões do encarceramento e desafios da política penitenciária no Brasil. Revista Brasileira de Ciências Criminais, 24(126), 291-331.

Zaffaroni, R. E. (1991). La filosofía del sistema penitenciario en el mundo contemporáneo. In M. A. Beloff et al. (Orgs.), Cuadernos de la cárcel (pp. 36-62). Buenos Aires. 
Jaqueline Oliveira Bagalho, Mestre em Psicologia/UFES, Doutoranda do Programa de Pós-Graduação em Psicologia da Universidade Federal do Espírito Santo, é Professora do curso de Graduação em Psicologia da Associação Vitoriana de Ensino Superior (FAVI). Endereço para correspondência Rua Desembargador Eurípedes Queiroz do Vale, n. 56/Apto 801 Jardim Camburi, Vitória/ES, CEP 29.090-090.

E-mail: jaquelinebagalho@gmail.com

Thiago Drumond Moraes, Doutor em Psicologia Social/UERJ, Pósdoutorado em Ergologia/Aix-Marseille Université, é Professor do Departamento de Psicologia Social e do Desenvolvimento/

Programa de Pós-Graduação em Psicologia/Universidade Federal do Espírito Santo (UFES). E-mail: thiago.moraes@ufes.br

Recebido em 29.Ago.16

Revisado em 27.Mai.17 Aceito em 19.Jul.17 